\title{
The role of ultrasonography in head and neck Non-Melanoma Skin Cancer approach: an update with a review of the literature
}

\author{
Tiberiu Tamaș ${ }^{1}$, Cristian Dinu1, Manuela Lenghel², Grigore Băciuț ${ }^{1}$, Simion Bran1, \\ Sebastian Stoia ${ }^{1}$, Mihaela Băciut ${ }^{1}$
}

${ }^{1}$ Maxillofacial Surgery and Implantology Department, ${ }^{2}$ Radiology Department, “Iuliu Hatieganu” University of Medicine and Pharmacy, Cluj-Napoca, Romania

\begin{abstract}
Non-Melanoma Skin Cancer is one of the most common cancer types and the face is the most affected region. The diagnosis of the skin cancer relies on clinical inspection, palpation, dermoscopy followed by incisional or excisional biopsy. When skin cancers are removed from the face, many factors are involved, including aesthetics. In addition, surgical planning with preoperative acknowledgement of the tumour margins is often the key to avoid incomplete excision, the need for reintervention, or in the prevention of functional and aesthetical defects in the treatment of skin tumours. In recent years, the development of new technologies in sonography, including high frequencies transducers can provide a full range of data. It can offer valuable information regarding the size of the tumour including the depth of invasion, the extent of the tumour, histology and subtypes of the lesions which are helpful for the treatment plan. It also may be efficient in detection of positive margins after surgery and it could play a role in the treatment of skin cancer, prevention of local recurrences and overall control of the disease.
\end{abstract}

Keywords: ultrasonography; skin; cancer; head; neck

\section{Introduction}

Non-melanoma skin cancer (NMSC) is one of the most frequently diagnosed cancers and the incidence is still increasing [1-3]. The most common types are basal cell carcinomas (BCCs) $(80-90 \%)$ and squamous cell carcinomas (SCCs), with usually a good prognosis, especially when they are detected in initial stages [1]. The head and the neck region is the most involved anatomical area due to the high amount of ultraviolet radiation exposure. A large number of alternative approaches have been reported to manage NMSC but the first-choice ther-

Received 10.05.2020 Accepted 14.09.2020

Med Ultrason

2021, Vol. 23, No 1, 83-88

Corresponding author: Cristian Dinu

Department of Maxillofacial Surgery and Implantology, Faculty of Dentistry,

"Iuliu Hatieganu" University of Medicine and Pharmacy, 37 Cardinal Iuliu Hossu street, 400029, Cluj-Napoca, Romania

Phone: +40722621206

E-mail: cristian.dinu@umfcluj.ro apy is still surgical excision and it will always remain a challenge to obtain favourable aesthetical results $[1,4]$. Overestimation of the tumour area can lead to unnecessary tissue sacrifice and reconstruction challenge. On the other hand, incomplete excisions are charged with a high rate of recurrence and more aggressive behaviour.

The diagnosis of the skin cancer relies on clinical inspection, palpation, dermoscopy followed by incisional or excisional biopsy. With dermoscopy, it is possible to assess the extension of the lesion in the longitudinal and horizontal axes but not to determine its depth and the potential invasion of adjacent structures [5-7]. The American Joint Committee on Cancer (AJCC) staging system uses depth of invasion (DOI) in the staging of non-melanoma skin cancer which changes the staging in the case of an invasion greater than 6 millimeters. In addition, DOI is associated with the risk of regional metastases in the case of SCC and other aggressive skin cancers.

The role of imaging is not clearly established. Computed Tomography (CT) scan and magnetic resonance imaging (MRI) can be helpful in the case of large tumours invading adjacent structures and for the staging 
in cases of regional metastasis. The disadvantages are the high costs, the use of ionizing radiations in the case of the CT scan and their limitations in the case of small tumours. Ultrasound (US) examination can provide additional information such as the thickness of the tumour, the depth of invasion, the vascularity and the stiffness. It is easily accepted by the patient as it is a non invasive and non-irradiating imaging technique [8-10].

Since the structures of interest are only a few millimeters beneath the skin surface, high-frequency US is needed [11-13]. In the recent years, the development of new technologies, including high frequencies transducers, can provide a full range of data which include the exact anatomic location, shape, extent in all axes, blood flow and deeper layers involvement. Due to the higher frequencies, US provides higher resolution but decreases tissue penetration. Therefore, in clinical practice the ultrasonic transducers from 10 to $40 \mathrm{MHz}$ are commonly used to estimate the skin tumour thickness $[14,15]$.

High frequency US showed good results in measuring the DOI preoperatively as shown in the prospective study of Song. et al [16]. For this, the depth of the lesion is measured from the epidermal granulous layer to the deepest point of invasion. Access to prognostic features of skin cancers, such as depth of invasion measured by the ultrasound system, would offer guidance in defining surgical margins and early planning of treatment options. Moreover, US allows for a 3-dimensional (3D) analysis of the tumour which may help prevent poor postsurgical outcomes.

The aim of this paper is to review the literature in order to assess the role of US in the diagnosis and treatment of the NMSC of the head and neck.

\section{Technical considerations}

High-resolution equipment with high-frequency probes $(15-40 \mathrm{MHz})$ is used and hockey stick-shaped probes are recommended due to their better adaptation. A grayscale examination in a minimum 2 axes should be performed, which can be followed by color or power Doppler US scan of the lesion. In order to improve the presentation and the understanding of the referring clinicians, 3D reconstructions can be used. Measurements of all diameters (longitudinal, transverse and deep axes) should be registered. Description of the type, size and nature (arteries or veins) of the tumour vessels and the peak systolic velocity of the arterial vessels are also given. The presence of deeper layers such as cartilage, muscle and bone involvement are noted. The ultrasound report must include the shape, depth, echogenicity (hypoechoic, isoechoic and hyperechoic), homogeneity (homogenous and heterogeneous), size, level of invasion and vascularity. Special consideration is needed in order to avoid artefacts derived from crusted or ulcerated areas. The US beam needs to be applied perpendicular to the skin surface to minimize the pressure in order to ensure a better scan. The scan orientation is selected to display the greatest diameter and thickness of the focal lesions $[17,18]$.

Optical coherence tomography (OCT), a high-resolution technique based on the properties of light, has also been reported for studying skin carcinomas. According to the literature, OCT appears to be more precise and less biased than high-frequency US for thickness measurement in the BCC lesions smaller than 2 [19-22].

Confocal microscopy, also called reflectance confocal microscopy, and multiphoton microscopy are other high-resolution imaging techniques that provides in vivo images almost comparable to histologic analysis in BCC lesions. In contrast to previous cross-sectional imaging techniques, a horizontal perspective of the tumour in grayscale is shown [23-25].

B-mode US and strain elastography can be used to scan the longitudinal and transverse planes of the skin tumours. Minimal compression with transducer and copious gel is applied during the examination. The skin tumour is measured with B-mode US as the longest axis of the hypoechoic lesion. Hyperechoic dots are registered if present, as well as intralesional vascularization with color Doppler US, with parameters adjusted for superficial slow velocities. The recorded elastograms are replayed to select the best representative image, which was defined as the image with adequate detection of the tissue structure and constant reproduction of the scanned images. On the color-coded strain elastogram, the soft and the hard tissue are coded differently by using colors. Regions of interest of BCCs are manually delineated by following B-mode margins [26,27].

A particular evaluation of the tumour can be performed after surgical removal for margins' measurement. The tumour needs to be placed with the epidermis facing up on sterile gauze and fixed with small-gauge needles. A layer of US gel is applied. A high frequency probe should be used. The settings of the US machine vary according to the manufacturer's instructions. The examination of the surgical specimen should cover all axes. After examination of the images, the lateral margins and the deep margin should be measured [17].

\section{Diagnostic value of US for head and neck skin tumours diagnosis}

Usually, NMSC is hypoechoic, inhomogenous on grayscale US examination. The DOI can be measured 


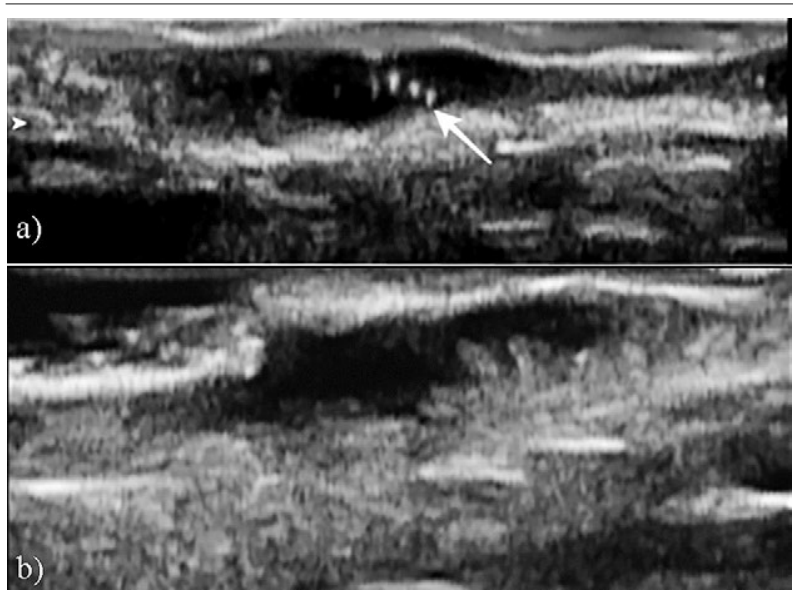

Fig 1. a) High-resolution ultrasound ( $40 \mathrm{MHz}$ ) in a 76 year-old patient with basal cell carcinoma (BCC) on the left cheek showing a well-defined hypoechoic lesion; also note the hyperechoic spot (arrow), highly suggestive for BCC; b) High-resolution ultrasound $(40 \mathrm{MHz})$ in a patient with cutaneous squamous cell carcinoma on the right parotid region, with hypoechoic appearance and infiltrative margins, no hyperechoic spots identified.

from the epidermal surface to the deepest infiltration point $[27,28]$. A greater value of DOI can be associated with a more aggressive tumour. Grayscale US can be used also in histological differentiation. According to Alfgame et al [29] and Wortsman et al [17], BCC can be differentiated from other cutaneous tumours and also different types of $\mathrm{BCC}$ can be differentiated by US. On grayscale US, BCC tumours tend to appear as well-defined oval hypoechoic or heterogeneous dermal structures (fig 1).

Commonly, BCCs have hyperechoic spots, which may be a useful sign to differentiate this tumour from

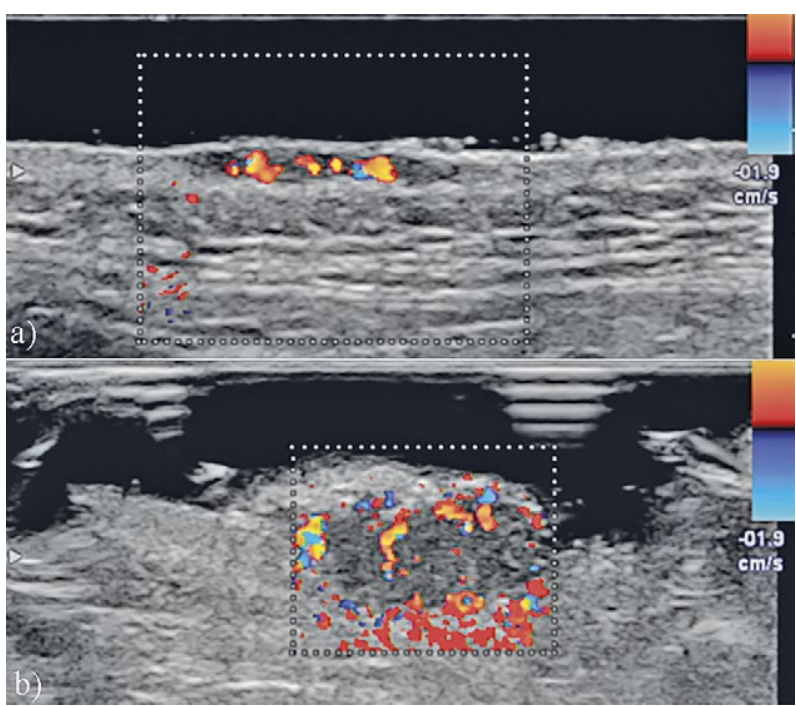

Fig 2. Color Doppler US demonstrating increased vascular signal both on BCC (a) and SCC (b) other types of skin cancer. These hyperechoic spots have a cotton flower-like appearance without posterior acoustic shadowing [30]. These spots appear to correlate on histologic analysis with the presence of horn cysts, microcalcifications or clusters of apoptotic cells in the centre of nests of basal cell carcinomas. The presence of more than 7 spots can be suggestive for a more aggressive histologic type. The micronodular subtype is associated with the largest number of hyperechoic spots [14].

Colour and power Doppler US may be helpful in identifying the blood flow patterns. The device settings must be set for superficial slow flow. If the transducer pressure on the skin is too high, the Doppler flow signals can be suppressed, so a light touch should be applied. The skin cancer appears usually well vascularised with mixed pattern, with internal and peripheral vascularization (fig 2). Peritumoral blood flow is discrete and consists of arteries and veins of low flow [26,27,31].

Elastography is an ultrasound (US) based image modality that assesses tissue elasticity. Elastography may be useful in differentiating malignant from benign skin tumours, and, in some cases, BCC from SCC (fig 3).

The elastography can also be useful to differentiate infiltrative $\mathrm{BCC}$ from the non-infiltrative type and can achieve with higher accuracy the DOI than grayscale sonography $[14,32]$. In strain elastography, the strain value represents an indirect measure of elasticity, or tissue stiffness. Cutaneous layers exhibit different elastic properties, with the epidermis and dermis being less elastic (lower strain) and subcutaneous tissue being more elastic (higher strain). The presence of increased marginal stiffness can be highly suggestive for malignancy. The

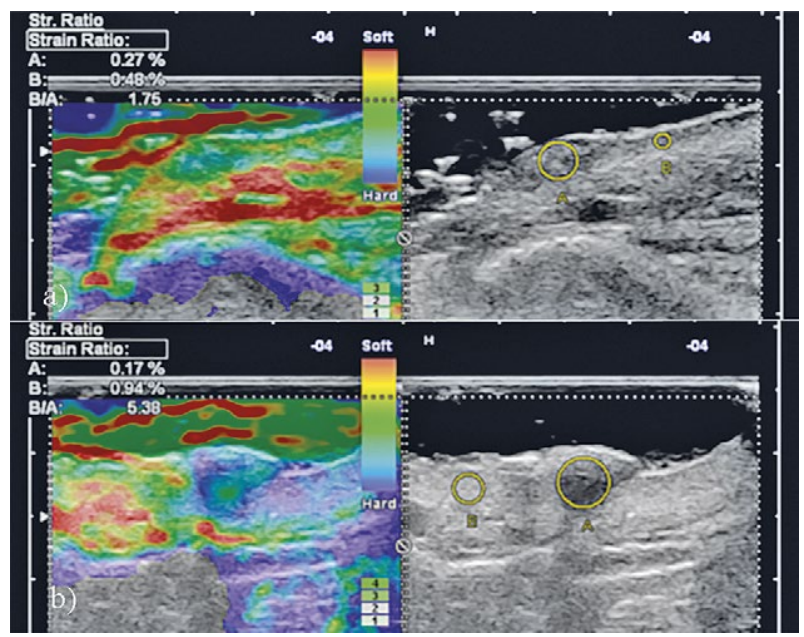

Fig 3. Strain-elastography ultrasound using a $13 \mathrm{MHz}$ frequency transducer and a gel pad, with the measurement of the strain ratio (SR), showing a softer appearance on BCC (a) compared with SCC (b) 
stiffness can be also correlated with the invasion of the tumour, which means stiffer tumours are more aggressive and invasive. This should be important in the treatment plan, a more extended surgery being possibly necessary. Carcinoma creates a fibrotic environment leading to an increased stiffness compared with the surrounding tissues $[14,32]$.

\section{Relevant data from the recent literature}

There are very few studies in the literature referring to US role in NMSC diagnosis. Among these, 4 studies have included only tumours from the head and neck region. Three studies are prospective and one retrospective. One-hundred sixty-seven patients with 176 head and neck non-melanoma skin cancer were investigated by US. Three articles are strictly pertaining to BCC and one to all non-melanoma skin cancers. The US transducers frequency varied between 5-18 MHz. Shape, depth of invasion, echogenicity, size, vascularity and hyperechoic spots were examined.

In one of these studies [29] the authors concluded that elastography is a variable evaluation, which together with B-mode findings, may offer valuable information for the clinician or the surgeon about subtypes of BCC. More precisely, increased marginal stiffness differentiates infiltrative from non-infiltrative cutaneous basal cell carcinomas. Tanaka et al demonstrated in their study, which included also other regions, not just the head and neck, that the tumour thickness of nodular BCC measured by elastography correlated better with the histological thickness in comparison with tumour thickness measured by conventional B-mode sonography [33]. Based on these studies, elastography can be a reliable method for planning the future surgical safety margins due to the higher risk of recurrence in the case of the infiltrative variant of BCC.

Wortsman et al [15] summarized that US examination of BCC tumours may evaluate characteristic hyperechoic spots which can confirm the diagnosis and also help in the prediction of high recurrence risk histologic subtypes. Other studies including NMSC concluded that hyperechoic spots can be visualised on grayscale US and can differentiate BCC from other tumours $[28,32,35,36]$.

Song et al [16] found an excellent correlation comparing the depth of invasion of the skin lesions measured on ultrasound and on histology. As we mentioned before, assessing all three dimensions of the tumour (length, width and depth) is mandatory, especially when the updated AJCC staging system uses depth of invasion in staging of non-melanoma skin cancer. In addition, depth of invasion is associated with the risk of regional metastases in case of SCC and other aggressive skin cancers. Unfortunately, dermoscopy or skin biopsy cannot evaluate the depth of invasion preoperatively. Some of the clinicians prefer biopsy of suspicious skin lesions but assessing the DOI can be challenging and the technique can be difficult when the tumour has a small size $[37,38]$.

Table I. Relevant data from the literature regarding the role of US in NMSC of the head and neck region

\begin{tabular}{|c|c|c|c|c|c|c|c|}
\hline Nr. & Authors & Study type & $\mathbf{N}$ & Histology & Transducer & Objective & Conclusion \\
\hline 1 & $\begin{array}{l}\text { Alfgame, } \\
2018 \text { [29] }\end{array}$ & Prospective & 31 & $\mathrm{BCC}$ & $\begin{array}{l}8-18 \\
\mathrm{MHz}\end{array}$ & $\begin{array}{l}\text { To differentiate infiltrative } \\
\text { from noninfiltrative BCCs } \\
\text { on elastography }\end{array}$ & $\begin{array}{l}\text { Increased marginal stiffness differ- } \\
\text { entiates infiltrative from noninfil- } \\
\text { trative cutaneous BCC }\end{array}$ \\
\hline 2 & $\begin{array}{l}\text { Vilas-Sueiro, } \\
2018[34]\end{array}$ & Prospective & 65 & $\mathrm{BCC}$ & $\begin{array}{l}10-18 \\
\mathrm{MHz}\end{array}$ & $\begin{array}{l}\text { To use ultrasound for } \\
\text { assessing the margins by } \\
\text { imaging the surgical } \\
\text { specimen once excised }\end{array}$ & $\begin{array}{l}\text { Ultrasound can detect margin } \\
\text { involvement and therefore may } \\
\text { play a role in the treatment of skin } \\
\text { cancer and prevention of local } \\
\text { recurrences }\end{array}$ \\
\hline 3 & $\begin{array}{l}\text { Song, } \\
2014 \text { [16] }\end{array}$ & Prospective & 49 & $\begin{array}{l}\text { All } \\
\text { NMSC }\end{array}$ & $\begin{array}{l}5-17 \\
\mathrm{MHz}\end{array}$ & $\begin{array}{l}\text { To compare the accuracy } \\
\text { of the ultrasound system } \\
\text { in vivo and to correlate the } \\
\text { results with the histopatho- } \\
\text { logical tumour thickness } \\
\text { measured in skin cancer } \\
\text { patients }\end{array}$ & $\begin{array}{l}\text { Excellent correlation between the } \\
\text { comparison of the depth of inva- } \\
\text { sion in skin lesions measured on } \\
\text { ultrasound and on histology }\end{array}$ \\
\hline 4 & $\begin{array}{l}\text { Wortsman, } \\
2014 \text { [17] }\end{array}$ & $\begin{array}{l}\text { Retro- } \\
\text { spective }\end{array}$ & 31 & $\mathrm{BCC}$ & $\begin{array}{l}12.5-18 \\
\mathrm{MHz}\end{array}$ & $\begin{array}{l}\text { To evaluate the rela- } \\
\text { tionship between BCC } \\
\text { histologic subtypes linked } \\
\text { to high and low risk of re- } \\
\text { currence and the presence } \\
\text { of hyperechoic spots on } \\
\text { sonography. }\end{array}$ & $\begin{array}{l}\text { BCC tumours generate character- } \\
\text { istic hyperechoic spots which can } \\
\text { confirm the diagnosis and also help } \\
\text { in the prediction of high recurrence } \\
\text { risk histologic subtypes }\end{array}$ \\
\hline
\end{tabular}


Regarding the role US in the treatment of NMSC, Vilas-Sueiro et al [34] demonstrated in their study on ex-vivo specimen margins that US can readily detect margin involvement and therefore may play a role in the treatment of skin cancer and prevention of local recurrence and thus, provide improved overall success and survival rates. Mohs surgery is a method of skin cancer removal named in honour of the surgeon who developed the technique, Frederick Mohs. This surgical approach offers high cure rates in the treatment of a variety of skin cancers by precise microscopic control of the entire tumour margin [39]. Unfortunately, it is not available in all treatment centres. Without this technique, evaluating margins status before histological report is almost impossible. Nolan et al started a new design for a meta-analysis in which they will summarise the best available evidence in order to establish the incidence of incomplete surgical excision in non-melanoma skin cancer [40].

All the relevant data assessing the role of US in NMSC of the head and neck are summarized in Table I.

\section{Conclusion}

The development of new technologies in US, including high-frequency transducers and elastography can be considered reliable tools in the management of non-melanoma skin cancer of the head and neck region. It can offer valuable information regarding the size of the tumour including the depth of invasion, the extent of the tumour, histology and subtypes of the lesions which are helpful for the treatment plan. It also may be efficient in the detection of positive margins after surgery and it could play a role in the treatment of skin cancer, prevention of local recurrences and overall control of the disease.

\section{Conflict of interest: None}

\section{Bibliography}

1. Didona D, Paolino G, Bottoni U, Cantisani C. Non-Melanoma Skin Cancer Pathogenesis Overview. Biomedicines 2018;6:6.

2. Leiter U, Eigentler T, Garbe C. Epidemiology of skin cancer. Adv Exp Med Biol 2014;810:120-140.

3. Katalinic A, Kunze U, Schafer T. Epidemiology of cutaneous melanoma and non-melanoma skin cancer in Schleswig-Holstein, Germany: Distribution, clinical subtypes, tumour stages and localization. Br J Dermatol 2003;149:1200-1206.

4. Calzavara-Pinton P, Ortel B, Venturini M. Non-melanoma skin cancer, sun exposure and sun protection. G Ital Dermatol Venereol 2015;150:369-378.

5. Barcaui EO, Carvalho AC, Valiante PM, Barcaui CB. Highfrequency ultrasound associated with dermoscopy in pre- operative evaluation of basal cell carcinoma. An Bras Dermatol 2014;89:828-831.

6. Altamura D, Menzies SW, Argenziano G, et al. Dermatoscopy of basal cell carcinoma: Morphologic variability of global and local features and accuracy of diagnosis. J Am Acad Dermatol 2010;62:67-75.

7. Nassiri-Kashani M, Sadr B, Fanian F, et al. Pre-operative assessment of basal cell carcinoma dimensions using high frequency ultrasonography and its correlation with histopathology. Skin Res Technol 2013;19:e132-e138.

8. Crișan D, Badea AF, Crișan M, Rastian I, Gheuca Solovastru L, Badea R. Integrative analysis of cutaneous skin tumours using ultrasonogaphic criteria. Preliminary results. Med Ultrason 2014;16:285-290.

9. Crisan M, Crisan D, Sannino G, Lupsor M, Badea R, Amzica F. Ultrasonographic staging of cutaneous malignant tumors: an ultrasonographic depth index. Arch Dermatol Res 2013;305:305-313.

10. Badea R, Crisan M, Lupsor M, Fodor L. Diagnosis and characterisation of cutaneous tumors using combined ultrasonographic procedures (conventional and high resolution ultrasonography). Med Ultrason 2010;12:317-322.

11. Bhatt KD, Tambe SA, Jerajani HR, Dhurat RS. Utility of high-frequency ultrasonography in the diagnosis of benign and malignant skin tumors. Indian J Dermatol Venereol Leprol 2017;83:162-182.

12. Jasaitiene D, Valiukeviciene S, Linkeviciute G, Raisutis R, Jasiuniene E, Kazys R. Principles of high-frequency ultrasonography for investigation of skin pathology. J Eur Acad Dermatol Venerol 2011;25:375-382.

13. Bezugly A. High frequency ultrasound study of skin tumors in dermatological and aesthetic practice. Med Ultrason 2015;17:541-544.

14. Alfageme Roldan F. Elastography in dermatology. Actas Dermosifiliogr 2016;107:652-660.

15. Wortsman X. Sonography of facial cutaneous basal cell carcinoma: a first-line imaging technique. J Ultrasound Med 2013;32:567-572.

16. Song WJ, Choi HJ, Lee YM, et al. Clinical analysis of an ultrasound system in the evaluation of skin cancers: correlation with histology. Ann Plast Surg 2014;73:427-433.

17. Wortsman X, Vergara P, Castro A, et al. Ultrasound as predictor of histologic subtypes linked to recurrence in basal cell carcinoma of the skin. J Eur Acad Dermatol Venereol 2015;29:702-707.

18. Schmid-Wendtner MH, Burgdorf W. Ultrasound scanning in dermatology. Arch Dermatol 2005;141:217-224.

19. Ferrante di Ruffano L, Dinnes J, Deeks JJ, et al. Optical coherence tomography for the diagnosis of skin cancer in adults. Cochrane Database Syst Rev 2018;12:CD013189.

20. Markowitz O, Schwartz M, Feldman E, et al. Evaluation of optical coherence tomography as a means of identifying earlier stage basal cell carcinomas while reducing the use of diagnostic biopsy. J Clin Aesthet Dermatol 2015;8:1420.

21. Olmedo JM, Warschaw KE, Schmitt JM, Swanson DL. Optical coherence tomography for the characterization of 
basal cell carcinoma in vivo: a pilot study. J Am Acad Dermatol 2006;55:408-412.

22. Gambichler T, Orlikov A, Vasa R, et al. In vivo optical coherence tomography of basal cell carcinoma. J Dermatol Sci 2007;45:167-173.

23. Sauermann K, Gambichler T, Wilmert M, et al. Investigation of basal cell carcinoma [correction of carcionoma] by confocal laser scanning microscopy in vivo. Skin Res Technol 2002;8:141-147.

24. Nori S, Rius-Díaz F, Cuevas J, et al. Sensitivity and specificity of reflectance-mode confocal microscopy for in vivo diagnosis of basal cell carcinoma: a multicenter study. J Am Acad Dermatol 2004;51:923-930.

25. Patalay R, Talbot C, Alexandrov Y, et al. Multiphoton multispectral fluorescence lifetime tomography for the evaluation of basal cell carcinomas. PLoS One 2012;7:e43460.

26. Dasgeb B, Morris MA, Mehregan D, Siegel EL. Quantified ultrasound elastography in the assessment of cutaneous carcinoma. Br J Radiol 2015;88:20150344.

27. Nakajima M, Kiyohara Y, Shimizu M, Kobayashi M. Clinical application of real time tissue elastography on skin lesions. Medix 2007;Suppl:36-39.

28. Lee SY, Hwang WJ, Kim KP, Kim HM, Hwang JH, Kim KS. The Relationship between the Size and the Invasion Depth of Tumors in Head and Neck Cutaneous Squamous Cell Carcinoma. Arch Plast Surg 2016;43:538-543.

29. Alfageme F, Salgüero I, Nájera L, Suarez ML, Roustan G. Increased marginal stiffness differentiates infiltrative from noninfiltrative cutaneous basal cell carcinomas in the facial area: a prospective study. J Ultrasound Med 2019;38:18411845.

30. Uhara H, Hayashi K, Koga H, Saida T. Multiple hypersonographic spots in basal cell carcinoma. Dermatol Surg 2007;33:1215-1219.

31. Barcaui Ede O, Carvalho AC, Lopes, FP, Piñeiro-Maceira J, Barcaui CB. High frequency ultrasound with color
Doppler in dermatology. An Bras Dermatol 2016;91:262273.

32. Morris MA, Ring CM, Managuli R, et al. Feature analysis of ultrasound elastography image for quantitative assessment of cutaneous carcinoma. Skin Res Technol 2018;24:242-247.

33. Tanaka T, Tada Y, Ohnishi T, Watanabe S. Usefulness of real-time tissue elastography for detecting the border of basal cell carcinomas. J Dermatol 2017;44:438-443.

34. Vilas-Sueiro A, Alfageme F, Salgüero I, De Las Heras C, Roustan G. Ex Vivo High-Frequency Ultrasound for Assessment of Basal Cell Carcinoma. J Ultrasound Med 2019;38:529-531.

35. Kaikaris V, Samsanavicius D, Maslauskas K, et al. Measurement of melanoma thickness - comparison of two methods: ultrasound versus morphology. J Plast Reconstr Aesthet Surg 2011;64:796-802.

36. Khlebnikova AN, Molochkov VA, Selezneva EV, Belova LA, Bezugly VA, Molochkov AV. Ultrasonographic features of superficial and nodular basal cell carcinoma. Med Ultrason 2018;20:475-479.

37. Gambichler T, Moussa G, Bahrenberg K, et al. Preoperative ultrasonic assessment of thin melanocytic skin lesions using a $100-\mathrm{MHz}$ ultrasound transducer: a comparative study. Dermatol Surg 2007;33:818-824.

38. Khlebnikova A, Molochkov V, Selezneva E, et al. Basal cell carcinoma invasion depth determined with 30 and $75 \mathrm{MHz}$ high-frequency ultrasound and histopathology - a comparative study. Med Ultrason 2020;22:31-36.

39. Prickett KA, Ramsey ML. Mohs Micrographic Surgery. Stat Pearls Publishing; 2019.

40. Nolan GS, Wormald JCR, Kiely AL, Totty JP, Jain A. Global incidence of incomplete surgical excision in adult patients with non-melanoma skin cancer: study protocol for a systematic review and meta-analysis of observational studies. Syst Rev 2020;9:83. 